\title{
Peningkatan Kemampuan IP Dan Routing Dinamis Menggunakan Simulasi Cisco Paket Tracer Bagi Guru SMK Walisongo Semarang
}

\author{
Whisnumurti Adhiwibowo ${ }^{1}$, Susanto ${ }^{2}$, Alauddin Maulana Hirzan ${ }^{3}$ \\ 1,2,3Universitas Semarang \\ e-mail: ${ }^{1}$ whisnu@usm.ac.id, ${ }^{2}$ susanto@usm.ac.id, ${ }^{3}$ maulanahirzan@usm.ac.id
}

\begin{abstract}
Abstrak
Perkembangan dunia komunikasi jaringan komputer memiliki peran yang sangat penting untuk pertumbuhan berbagai sektor. Sektor-sektor yang berpengaruh seperti dunia pendidikan hingga ekonomi sangat terpengaruh akan adanya jaringan komputer. Dikarenakan pertumbuhan teknologi inilah mendorong orang-orang untuk mempelajarinya agar bisa diterapkan ke tempat kerja. Industri-industri juga membutuhkan orang-orang yang ahli di bidang jaringan untuk membantu mendorong kinerja industri. Oleh karena itu para guru khususnya guru SMK juga memiliki kewajiban memiliki kemampuan yang diperlukan untuk dunia kerja sebelum diajarkan ke para siswa. Kemampuan serta pemahaman mengenai pengaturan IP dan Routing secara otomatis dan dinamis belum diajarkan sepenuhnya, sehingga dapat menghambat pemberian materi ke para siswa. Materi-materi ini dikenal sebagai expertise atau ilmu keahlian khusus yang dapat diakses melalui akademi/institusi tertentu saja. Pengabdian ini memiliki tujuan mengajarkan IP dan Routing kepada para guru SMK Walisongo Semarang, sehingga para guru memiliki kemampuan serta pemahaman yang dapat diajarkan kepada para siswa dan tetap memiliki standar yang sama dengan keinginan industri. Proses peningkatan kemampuan ini disampaikan dengan metode ceramah dan disertai dengan asistensi langsung untuk memastikan para peserta dapat mencoba secara langsung materi yang diberikan. Dari kegiatan yang dilaksanakan ini, para peserta mengalami kenaikan pemahaman mencapai $46 \%$. Sehingga bisa dipastikan kegiatan peningkatan kemampuan ini berjalan dengan baik.
\end{abstract}

Kata Kunci: Routing, Packet Tracer, IP Dinamis

\section{Abstract}

The development of computer network telecommunication has an important role to help the growth of many sectors. There are many sectors such as education and economy sectors which are affected by the development of computer networks. Because of this reason, many people study how to implement them into a workspace. Many industries required skilled technicians or someone with expert knowledge about networking to help to grow their industry. Hence, all teachers especially vocational school teachers should have the proper knowledge needed by the industries. The knowledge and expertise about configuring dynamic IP and Routing are not fully learned by the teachers and might be slowing down the teaching progress to the students. These kinds of materials are considered expert knowledge which can be accessed through certain 
academies or institutions. This community service has a purpose to transfer knowledge about Dynamic IP and Routing to the teachers in SMK Walisongo Semarang, so all the teachers have industrial-acceptable skills and knowledge for the students. To increase the knowledge and understanding, the materials are delivered using oral lectures and accompanied with direct assistance to ensure that participants can try the material firsthand. From the activities carried out, the participants experienced an increase in understanding reaching $46 \%$. So it can be concluded that this activity successfully increases the participants' knowledge about dynamic IP and routing.

Keywords: Routing, Packet Tracer, Dynamic IP

\section{Pendahuluan}

Kebutuhan jaringan yang terkoneksi dengan internet semakin dibutuhkan dari tahun ke tahun. Banyaknya pengguna sosial media menjadikan internet menjadi kebutuhan utama, hal ini dapat dilihat dengan indikator meningkatnya kebutuhan bandwidth tiap tahun. Kebutuhan internet dan penggunaan sosial media menjadikan peningkatan akan kebutuhan perangkat keras dan jalur komunikasi(Novianty, 2019). Kebutuhan tersebut menjadikan peluang atau celah pekerjaan bagi lulusan kejuruan.

Peluang atau celah pekerjaan tersebut seharusnya dapat ditangkap oleh lulusan dari sekolah kejuruan(Perdana, 2019)(Hidayat \& Saleh, 2020). Untuk menangkap peluang tersebut dibutuhkan kemampuan atau ketrampilan untuk menciptakan lulusan yang memahami tentang jaringan komputer(Bidang et al., 2019).

Pemahaman yang harus dipahami tidak hanya sekedar komunikasi antar perangkat akan tetapi juga komunikasi berbeda jaringan atau berbeda virtualisasinya. Penggunakan Routing dinamis membantu para teknisi untung menghubungkan berbagai jenis jaringan hanya dengan perintah yang sederhana ke setiap perangkat. Selain pemberian alamat IP secara dinamis juga membantu para teknisi ketika melakukan pemberian alamat IP komputer dengan skala LAN hingga WAN secara otomatis tanpa harus konfigurasi manual satu per satu(Odom, 2016).

Kebutuhan pemahaman mengenai IP dan Routing dinamis sudah sulit untuk ditawar lagi, karena semakin banyak perangkat yang ada di jaringan maka semakin lama waktu yang diperlukan untuk konfigurasi manual. Selain itu, kebutuhan industri akan tenaga ahli jaringan juga sangat diperlukan untuk memelihara sistem yang dipunyai(Eze, 2017)(Prihatin Disas, 2018). Para guru yang bersekolah di SMK Walisongo Semarang dituntut untuk menguasai administrasi jaringan termasuk konfigurasi IP dan Routing dinamis dalam jaringan. Para guru ini masih kurang memiliki pemahaman dari konsep IP dan Routing dinamis dan bagaimana cara menyelesaikan masalah yang dihadapinya. Fokus mitra adalah bagaimana cara melakukan konfigurasi IP dan Routing Dinamis beserta penyelesaian masalahnya melalui perangkat lunak simulasi jaringan Cisco Packet Tracer untuk mempermudah pembangunan jaringan tanpa harus menggunakan perangkat aslinya(Cisco, 2017). 
Adapun tujuan dari diselenggarakannya Pengabdian ini adalah memberikan pelatihan pemahaman konfigurasi IP dan Routing dinamis dengan menggunakan Packet Tracer. Tujuan pengabdian mengacu pada permasalahan dan analisa situasi pada mitra. Perangkat lunak Packet Tracer ini dapat membantu para guru dalam memahami konfigurasi IP dan Routing dinamis dalam jaringan. Dengan meningkatkan kemampuan pemahaman konfigurasi IP dan Routing dinamis ini, maka diharapkan permasalahan mitra dapat terselesaikan dan semakin efisien dalam menyelesaikan pekerjaan.

Peningkatan kemampuan mengenai jaringan khususnya IP dan Routing Dinamis pernah dilakukan oleh pengabdi lainnya. Sebagai bukti nyata bahwa kemampuan mengenai jaringan benar-benar diinginkan oleh industri untuk dimanfaatkan sepenuhnya. Peningkatan kemampuan jaringan internet yang diselenggarakan oleh para pengabdi mampu mendorong motivasi kewirausahaan para siswa sehingga dapat mengurangi jumlah pengangguran yang ada(Maulita, 2018). Peningkatan ilmu ICT juga dilakukan dengan menggunakan perangkat router Cisco juga membantu para siswa SMK untuk mempelajari lebih jauh bagaimana proses pemberian IP dan Routing secara dinamis dan otomatis. Pelatihan ini dapat meningkatkan pengetahuan dan cara kerja dari perangkat Cisco ini(Anam et al., 2020). Peningkatan kemampuan guru tentu saja akan mempengaruhi keluaran dari siswa yang diajarkan. Sehingga diperlukanlah peningkatan kemampuan para guru sehingga dapat menghasilkan para siswa yang memiliki kemampuan maupun pemahaman mengenai jaringan(Angriani \& Rachman Dayat, 2019). Dalam dunia jaringan, pentingnya simulasi sebelum implementasi ke dunia nyata sangatlah penting. Hal ini dilakukan untuk menghindari kesalahan ketika melakukan implementasi. Oleh karena itu pemahaman mengenai Packet Tracer pun juga diajarkan kepada para guru agar dapat memberi pencerahan teknik desain yang sebenarnya menggunakan perangkat lunak simulasi ini(Sahrial Islam et al., 2019).

\section{Metode}

Metode yang digunakan dalam "Peningkatan Kemampuan IP dan Routing Dinamis Dengan Menggunakan Simulasi Cisco Paket Tracer Bagi Guru SMK Walisongo Semarang" akan diberikan dalam bentuk pelatihan secara langsung. Metode pelatihan yang dilakukan secara langsung akan memiliki tingkat pengaruh yang sangat signifikan terhadap penyerapan materi dan keterampilan berpikir kritis peserta hingga $77,28 \%$.

Untuk lokasi yang akan dituju dalam Pengabdian kepada Masyarakat ini berada di kabupaten Semarang tepatnya Jalan Ki Mangunsarkoro No.17, Karangkidul, Semarang Tengah, Brumbungan, Kec. Semarang Tengah, Kota Semarang, Jawa Tengah yang nantinya akan berlangsung selama 4 (empat) hingga 5 (lima) jam, dan perkiraan waktu pelaksanaan Pengabdian kepada Masyarakat akan dilakukan pada bulan Juni tahun 2020.

Masing-masing peserta menggunakan 1 unit komputer selama praktek berlangsung. Kegiatan dilaksanakan dalam 2 (satu) hari dengan durasi pelatihan adalah 4 (empat) jam, terdiri dari: 
1. 30 menit pengenalan Cisco Packet Tracer

2. 180 menit untuk pelatihan implementasi IP dan Routing Dinamis dengan asistensi langsung

3. Kemudian untuk evaluasi keseluruhan materi di hari berikutnya.

Evaluasi keberhasilan kegiatan pelatihan ini dilakukan setelah masing-masing sesi pelatihan dan pada akhir kegiatan. Setiap sesi pelatihan akan dilakukan evaluasi kemudian dilanjutkan evaluasi materi secara keseluruhan di akhir kegiatan. Indikator keberhasilan kegiatan ini dilihat dari respon positif dari para peserta melalui evaluasi yang diberikan. Evaluasi kegiatan juga dilakukan berupa kuesioner yang diisi peserta, terkait dengan kegiatan yang telah diikuti.

Kemampuan pemahaman peserta diperoleh berdasarkan hasil evaluasi terhadap peserta.

\section{Hasil dan Pembahasan}

Hasil ini diperoleh berdasarkan evaluasi-evaluasi dari tiap sesi yang diberikan, berikut analisa hasil dari evaluasi yang telah dilakukan pada Pengabdian kepada Masyarakat tentang "Peningkatan Kemampuan IP Dan Routing Dinamis Dengan Menggunakan Simulasi Cisco Paket Tracer Bagi Guru SMK Walisongo Semarang".

Proses penyampaian materi ini dilakukan dengan cara ceramah terlebih dahulu agar para peserta dapat memahami konsep dasar materi.

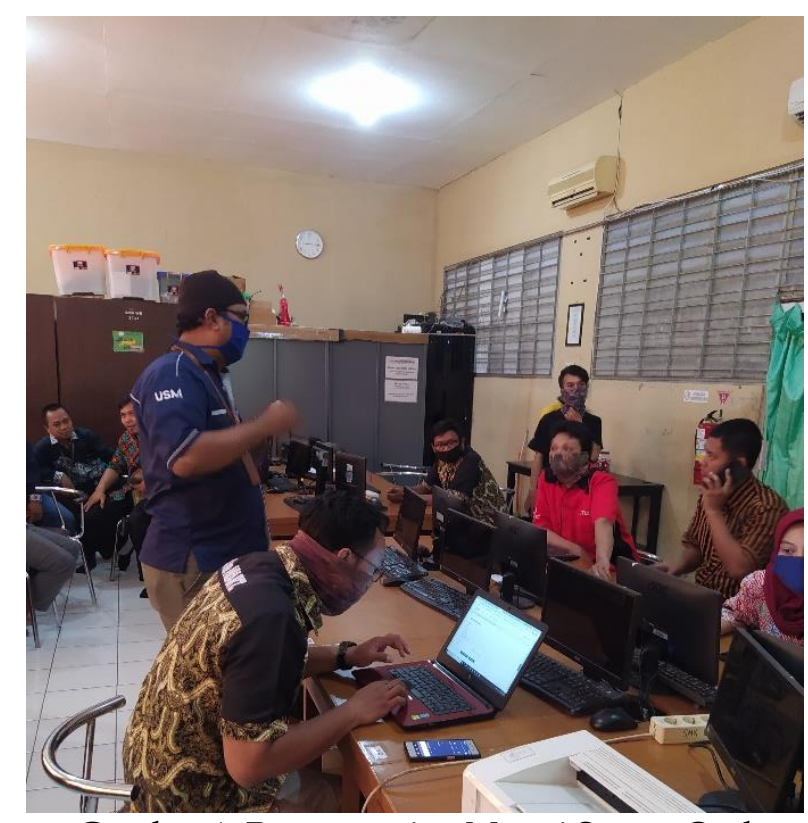

Gambar 1. Penyampaian Materi Secara Oral

Selain diberikan secara oral, para peserta juga mendapatkan asistensi langsung dari anggota tim sehingga dapat mempraktikkan serta menyelesaikan masalah secara langsung secara cepat dan tepat. 


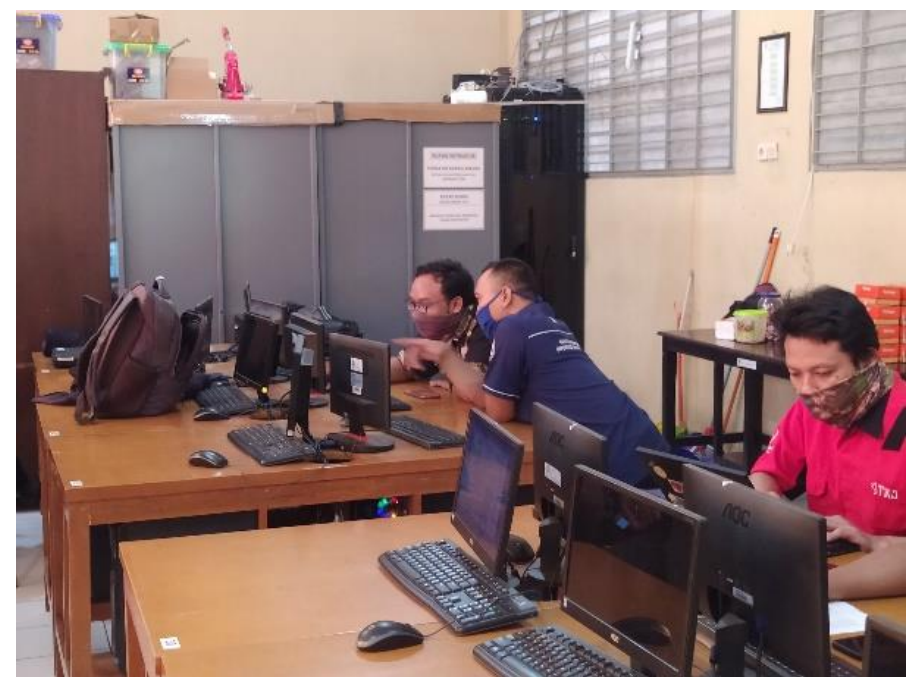

Gambar 2. Asistensi Peserta Ketika Mempraktikan Materi

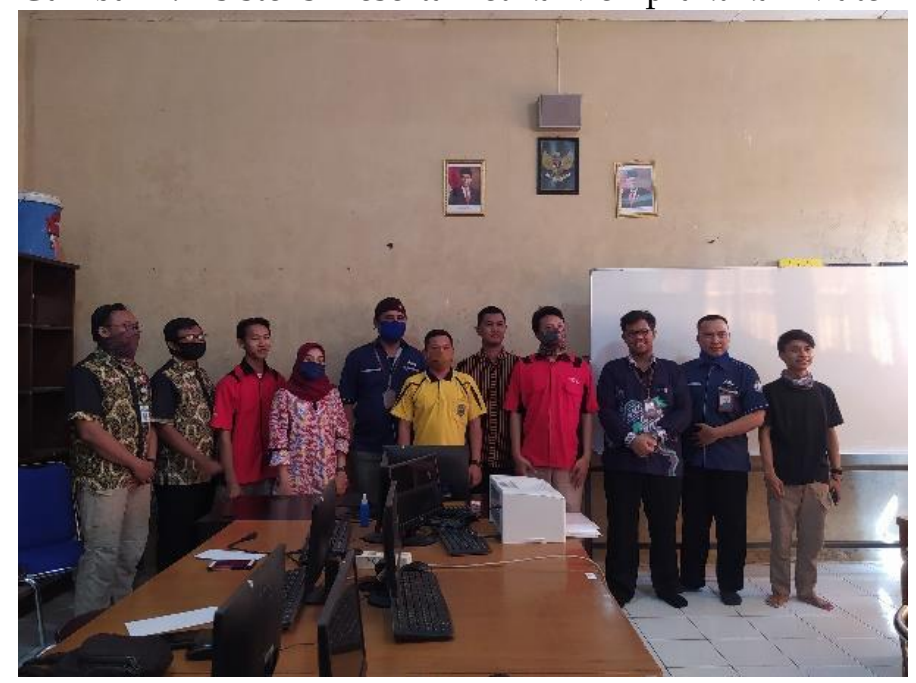

Gambar 3. Keseluruhan Peserta dan Tim Pengabdian

Hasil kuesioner dari pelatihan yang dilakukan ini kemudian diisi langsung oleh 10 orang peserta sebelum kegiatan dan sesudah kegiatan. Sehingga didapatkan peningkatan kemampuan seperti berikut:

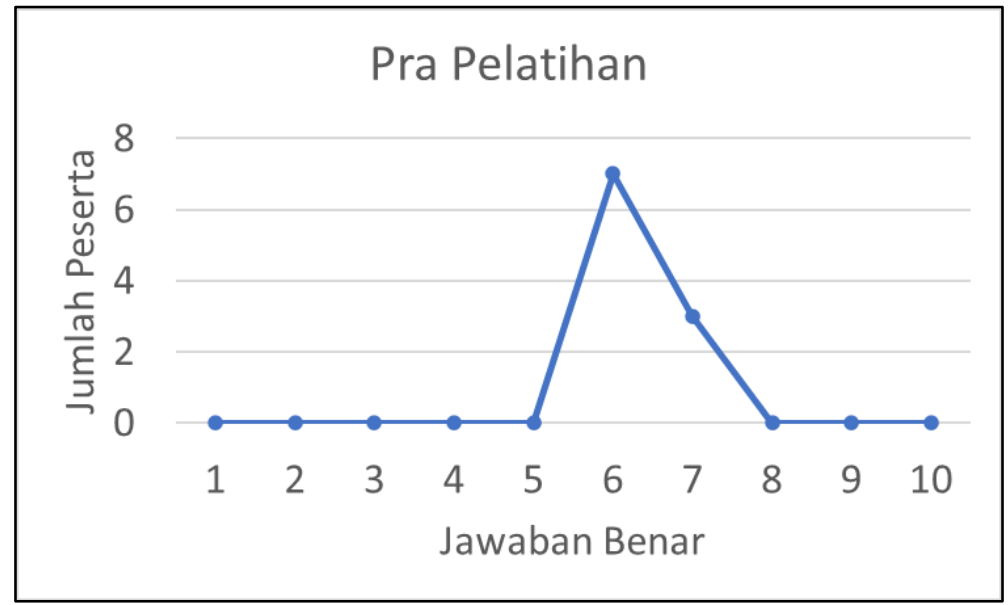

Gambar 4. Grafik Kurva Kuesioner Pra-Pelatihan 
Gambar 1 di atas merefleksikan hasil kuesioner pra-pelatihan yang diberikan sebelum proses pelatihan diberikan kepada para peserta di SMK Walisongo Semarang. Berdasarkan grafik kurva di atas, para peserta hanya dapat menjawab kuesioner dengan nilai tertinggi 6 poin sebanyak 7 orang peserta, dan 7 poin sebanyak 3 orang peserta. Pemahaman peserta berdasarkan kuesioner ini hanya mencapai $63 \%$ saja, kurang dari $37 \%$ dari para peserta yang masih belum menguasai materi.

Sehingga bisa dipastikan bahwa para peserta masih belum memahami secara penuh bagaimana konfigurasi IP dan Routing secara dinamis dilakukan dengan menggunakan router Cisco.

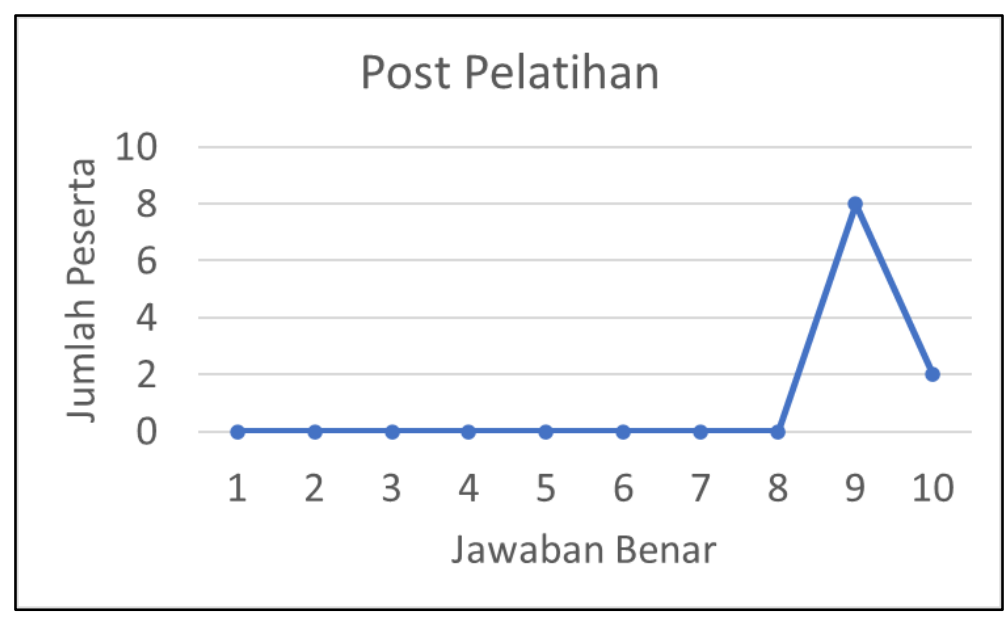

Gambar 5. Grafik Kurva Kuesioner Paska Pelatihan

Gambar 2 di atas merupakan refleksi hasil dari pelatihan yang diberikan kepada para peserta di SMK Walisongo Semarang. Berbeda dengan hasil sebelumnya di gambar 1, dengan adanya pelatihan yang diberikan dapat meningkatkan pemahaman mengenai IP dan Routing Dinamis bagi para peserta. Berdasarkan hasil di atas, para peserta mengalami peningkatan pemahaman sebanyak 9 poin dari 8 orang, dan 10 poin dari 2 orang. Dari kuesioner setelah pelatihan ini para peserta telah mampu menjawab 92\% dari kuesioner yang diberikan. Sehingga dari data yang didapatkan di atas, para peserta mengalami peningkatan kemampuan mencapai $46 \%$ persen dari pemahaman materi yang telah diberikan.

\section{Simpulan dan Rekomendasi}

Para guru SMK Walisongo sebagai peserta pelatihan telah mendapatkan pelatihan peningkatan keterampilan dalam membangun IP dan Routing Dinamis dengan Cisco Packet Tracer. Peserta pelatihan telah mengetahui manfaat dari pelatihan ini, dan bagaimana cara membangunnya dengan menggunakan Packet Tracer. Peserta pelatihan dapat memanfaatkan jaringan ini untuk berbagai keperluan dari tingkat rumah hingga industri/perusahaan. Hampir seluruh peserta pelatihan sepakat setelah mendapatkan pelatihan, kemampuan dan keterampilan dalam mengembangkan jaringan IP dan Routing Dinamis menggunakan Cisco Packet Tracer. 
Saran dalam kegiatan semacam ini mungkin perlu durasi kegiatan yang lebih panjang dan focus pada satu materi dalam satu kegiatan. Materi yang diberikan juga dapat menggunakan studi kasus jenis pekerjaan yang dihadapi oleh peserta. Selain hal tersebut, untuk peserta juga harus lebih terdahulu memahami dan pernah menggunakan Packet Tracer untuk dapat mengikuti peserta yang lain. Karena pelatihan seperti ini perlu tahapan-tahapan untuk memahami topik yang diberikan.

\section{Penghargaan}

Ucapan terima kasih disampaikan kepada Lembaga Penelitian dan Pengabdian kepada Masyarakat Universitas Semarang yang telah mendanai kegiatan ini, seluruh guru TKJ SMK Walisongo yang dapat menghadiri pelatihan dan mahasiswa Fakultas Teknologi Informasi dan Komunikasi Universitas Semarang yang telah berpartisipasi dalam kegiatan ini.

\section{Daftar Pustaka}

Anam, M. K., Ulfah, A. N., Lizarti, N., Sudyana, D., \& Sari, D. (2020). Workshop Peningkatan Kemampuan Dasar Desain Jaringan Dan Cisco Router Siswa/i SMKS Ibnu Taimiyah. J-PEMAS STMIK Amik Riau, 1(1), 1-4. http://jurnal.stmikamik-riau.ac.id/index.php/J-PEMAS/article/view/591

Angriani, L., \& Rachman Dayat, A. (2019). Pkm Peningkatan Kompetensi Guru Dan Siswa Melalui Pelatihan Pemrograman Dan Jaringan Komputer Pada Sekolah Menengah Kejuruan Di Kota Jayapura. Jurnal Abdimas, 23(2), 92-98.

Bidang, D., Teknik, K., Jaringan, K., Kabupaten, D. I., \& Arifudin, C. (2019). Kesesuaian Kompetensi Keahlian Lulusan Sekolah Menengah Kejuruan (Smk) Dengan Kompetensi Kerja Dunia Usaha Dan Industri (Du/Di) Dalam Bidang Keahlian Teknik Komputer Jaringan (Tkj) Di Kabupaten Cirebon. In JURNAL: Vol. nn, No. nn (Issue 02). https:/ / doi.org/10.47685/MESTRO.V1I02.26

Cisco. (2017). Packet Tracer | Cisco NetAcad. Netacad.Com.

Eze, P. T. I. (2017). Employers Perception Of Computer-Based Competencies Required Of Technical College. Journal of Technology \& Vocational Education, 2(1), 154-168.

Hidayat, S., \& Saleh, M. (2020). Kemampuan Kerja antara Pekerja Lulusan SMA dan SMK di Industri Manufaktur: Studi Komparasi. VALID Jurnal Ilmiah. http://stieamm.ac.id/jurnal/index.php/valid/article/view/103

Maulita, Y. (2018). Pelatihan Teknisi Jaringan Internet Untuk Meningkatkan Jiwa Kewirausahaan Siswa Smk (IbM). Jurnal Teknik Informatika Kaputama, 1(2), 20142018. https:// doi.org/10.31227/osf.io/fbazu

Novianty, D. (2019). Generasi Milenial Kuasai Penggunaan Internet Indonesia pada Tahun 2018. Suara.Com.

Odom, W. (2016). Routing and Switching. In Cisco Press. 
Perdana, N. S. (2019). Analisis Permintaan Dan Penawaran Lulusan Smk Dalam Pemenuhan Pasar Tenaga Kerja. Refleksi Edukatika: Jurnal Ilmiah Kependidikan, 9(2), 172-181. https:/ / doi.org/10.24176/re.v9i2.2948

Prihatin Disas, E. (2018). Link and Match sebagai Kebijakan Pendidikan Kejuruan. Jurnal Penelitian Pendidikan.

Sahrial Islam, A., Ekohariadi, \& Pendidikan. (2019). Pemanfaatan Aplikasi Cisco Packet Tracer Untuk Meningkatkan Kemampuan Pada Mata Pelajaran Administrasi Infrastruktur Jaringan Berbantuan Modul Di Smkn 1 Sidayu Gresik. Jurnal IT-EDU, 04, 373426. 